\title{
Analysis of meteorological droughts in the Lake's Region of Ethiopian Rift Valley using reconnaissance drought index (RDI)
}

\author{
Yimer Mohammed ${ }^{*}$ (D) and Asnake Yimam
}

\begin{abstract}
This study investigated the intensity, trend and spatio-temporal variability of meteorological drought in the Lakes' Region of Ethiopian Rift Valley using monthly rainfall and maximum and minimum temperature records for the period 1986-2019. Reconnaissance Drought Index (RDI) was employed to generate the intensity of drought at 3 and 12-months timescale. Mann-Kendall trend test was used to determine the trend of the changes in the RDI time series. The spatial extent of droughts has been interpolated by inverse distance weighted (IDW) method using the spatial analyst tool of ArcGIS. Results indicated the occurrence of different intensity and trend signals across seasons and over space in the study area. A total of 33 extreme drought months were observed in all stations during summer with varying intensity ( -2.01 at Halaba to -3.52 at Wolaita) and 168 extreme drought months at annual timescale ranging from -2.10 at Hawassa to -4.51 at Wolaita. The intensity of drought events observed in Wolaita in 1986 at all timescales (RDI value of $-3.19,-3.52$ and -4.51 for spring, summer and annual respectively) were very extraordinary and devastating. Drought magnitude showed increasing signal at 6 out of 10 stations, although statistically significant at only two stations (Arsi Negelle at all timescale and Butajira at spring and annual timescale). However, the spatial patterns of drought events didn't exhibit clear pattern rather more localized distribution and variability. The frequency of drought incidence became intense in the study area from 2008 onwards at all timescales compared to the 1990s and 2000s. The increasing tendency of drought in recent years might be the manifestation of borderless global warming. The empirical evidences showed that drought events and their negative effects are highly localized in the study area and provide useful information for local-scale planning for drought management and response.
\end{abstract}

Keywords: Reconnaissance drought index, Inverse distance weighted, Belg, Kiremt, Ethiopia

\section{Introduction}

The warming of earth's climate system is unequivocal and the intensity and frequency of extremes are likely to increase over many areas (IPCC V 2014). The report highlighted that frequency and intensity of extremes like droughts, floods, and heat waves are expected to change as earth's climate changes. Droughts are one of the natural hazards which have devastating effects on the socioeconomic and environmental conditions. Droughts are

\footnotetext{
* Correspondence: yimermoh2013@gmail.com

Department of Geography and Environmental Studies, Dilla University, P.O.Box 419, Dilla, Ethiopia
}

\section{Springer Open}

(c) The Author(s). 2021 Open Access This article is licensed under a Creative Commons Attribution 4.0 International License, which permits use, sharing, adaptation, distribution and reproduction in any medium or format, as long as you give appropriate credit to the original author(s) and the source, provide a link to the Creative Commons licence, and indicate if changes were made. The images or other third party material in this article are included in the article's Creative Commons licence, unless indicated otherwise in a credit line to the material. If material is not included in the article's Creative Commons licence and your intended use is not permitted by statutory regulation or exceeds the permitted use, you will need to obtain permission directly from the copyright holder. To view a copy of this licence, visit http://creativecommons.org/licenses/by/4.0/.

resulted from many hydrometeorological processes that limit surface water or groundwater availability, creating conditions that are significantly drier than normal (WMO and GWP 2016).

Droughts have significant deleterious impact on many economic sectors and people at any one time. According to the Emergency Event Database, in the period 19952015 , even though drought accounted for less than 5\% of all natural hazards, more than one billion people were affected by droughts, that is more than a quarter of all people affected by all types of weather related disasters worldwide (CRED and UNISDR 2015). In this regard, 
drought characterization is vital, since it is the basis to find appropriate risk management measures by monitoring its intensity, frequency of occurrence and spatial distribution.

As it is indicated in Degefu and Bewket (2014) and Zargar et al. (2011), the impact of drought is governed by its intensity, duration, frequency and spatial extent of the precipitation deficit. Intensity refers to the amount of precipitation or water storage deficit at a particular place and specific time which is classified as mild, moderate, severe and extreme. Frequency is the average time between successive drought events and duration refers to the extent of time that a given drought event stays. The spatial coverage refers to the areal extent of a specific area affected by a given drought incidence. Usually severe and extreme drought episodes cover wider areas, while mild and moderate drought episodes tend to affect localized areas (Degefu and Bewket 2014).

Ethiopia is affected by frequent drought events that resulted in low crop and livestock productivity which in turn makes Ethiopia dependent on large humanitarian aid (Teshome and Zhang 2019). Ethiopia faced one of the worst droughts the country has seen in decades with over 10.2 million people in need of food aid (UN OCHA 2015). Triggered by El Niño, the rainy seasons in 2015 and 2016 failed so that the drought brought significant impact by limiting agricultural production, straining livelihoods, and exacerbating food insecurity among poor and vulnerable households. Every year, approximately three million Ethiopians are affected by crop production shortfalls adding to the 7.6 million supported every year by the Productive Safety Net Program, a social safety net supporting some of Ethiopia's poorest and most foodinsecure families (Cochrane and Tamiru 2016) because of extreme drought.

It is, therefore, very important to analyze drought events in Ethiopia which is continuously occurred over northern, northeastern, eastern and central parts of the country. Understanding the occurrence of extreme weather events especially rainfall is important for decisionmaking as it is a key factor in prediction and risk assessment (Teshome and Zhang 2019). Understanding drought conditions, societal vulnerability, and their related effects on one another provide us historical lessons that can aid in dealing with future drought conditions. Drought characterization at regional and local scales has significant implications for drought management. To help decision makers and the public address these issues, systematic assessments of meteorological drought is very crucial. The analysis and forecasting of extreme climatic events has become increasingly relevant to make planning effective. Understanding the features of droughts at the regional to local scale is a key for designing response measures that enhance preparedness and early warning systems, and additionally in the long term, it helps in the formulation of effective adaptation planning measures to reduce the related risks.

Many studies (for example, Edossa et al. 2010; Gebrehiwot et al. 2011; Viste et al. 2013; Degefu and Bewket 2014; Gizachew and Shimelis 2014; Muluneh et al. 2014; and Muluneh et al. 2016, Mohammed et al. 2017; Tesfamariam et al. 2019) were carried out to characterize the recurrent nation-wide and local-scale meteorological drought incidences in different parts of Ethiopia. However a few were conducted in this drought-prone rift valley lakes' region of Ethiopia. Gizachew and Shimelis (2014) studied vulnerability of the community to drought in rift valley areas of Ethiopia. Muluneh et al. $(2014,2016)$ studied on searching for evidences of changes in extreme rainfall indices and predicted the future precipitation and maize production in central rift valley (LRERV) of Ethiopia. However a few were conducted in this drought-prone rift valley lakes' region of Ethiopia. However, the study area is experiencing high temperature and potential evapotranspiration which has significant influence on the hydrology of the study area. In contrast this study characterized the spatial and temporal patterns of meteorological drought using Reconnaissance Drought Index (RDI) taking precipitation and potential evapotranspiration as an input for the model which help present reliable information about meteorological drought and design appropriate adaptation strategies. Therefore, the objective of this study was to analyze the intensity, frequency and spatiotemporal patterns of meteorological drought using RDI in the lakes' region of Ethiopian rift valley.

\section{Materials and methods}

\section{Description of the study area}

The study covers the lakes' region of Ethiopian rift valley which is located between $37^{\circ} 25^{\prime} \mathrm{E}$ and $39^{\circ} 28^{\prime} \mathrm{E}$ and between $5^{\circ} 45^{\prime} \mathrm{N}$ and $8^{\circ} 28^{\prime} \mathrm{N}$ (Fig. 1). It has an area of 41 , $549.7 \mathrm{~km}^{2}$.This area is one of the most unstable and environmentally vulnerable areas of the country (Muluneh et al. 2016). It is part of the Great East African Rift Valley and covers the major dry land parts of the country. The pattern of rainfall in the rift floor is more of stormy type with relatively high intensities (Makin et al. 1975).

There are eight major lakes, namely Koka, Ziway, Langano, Abiyata, Shala, Hawassa, Abaya and Chamo (Starting from north) (Fig. 1). The region is also characterized by three main seasons. The dry period (locally known as Bega) extends between September and February having occasional rains which account for about 10 $20 \%$ of the annual total, the small rainy season (locally known as Belg) occurs from March to May contributing $20-30 \%$ of the annual precipitation, and the long rainy season (locally known as Kiremt) is from June to August 


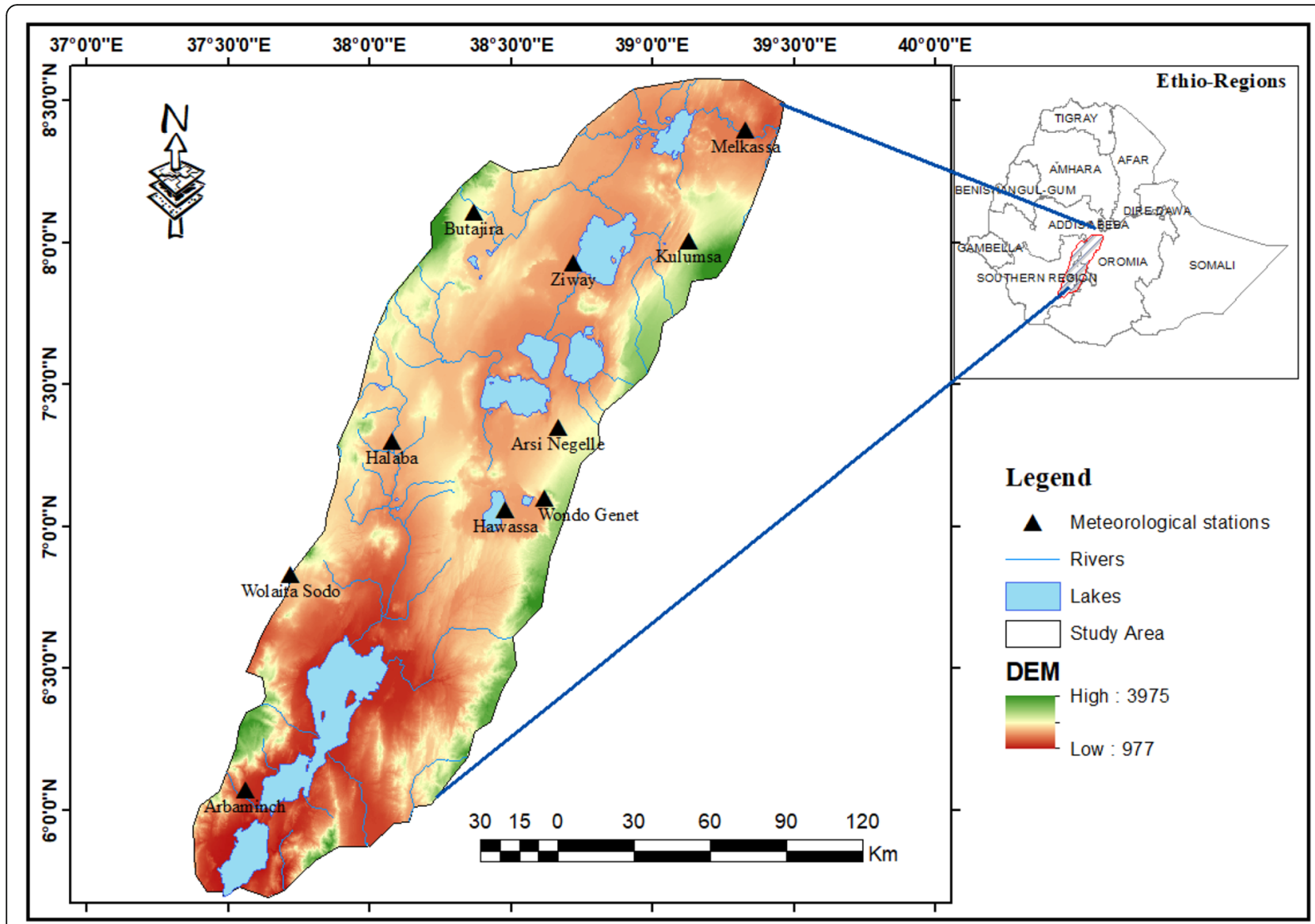

Fig. 1 Map of Lake Regions of ethiopian Rift Valley

during which $50-70 \%$ of the mean annual total precipitation is received (Legesse et al. 2004). The characteristics of rainfall in LRERV is more of stormy type with relatively high intensity.

The soils of the rift valley are largely derived fromrecent volcanic rock. The main parent materials are basalt, ignimbrites, lava, gneiss, volcanic ash, alluvium, and pumice. Some of the soil problems include lowphosphorus levels, micronutrient imbalances, and, insome cases; poor physical structure (Makin et al. 1975).

The distribution of plants in the study area is highly influenced by elevation which also impacts the precipitation pattern (Musein 2006). The rift valley floor is largely dominated by deciduous Acacia woodland and wooded grasslands that are increasingly becoming more open, whereas deciduous woodlands (Legesse et al. 2004).

\section{Data source}

Monthly minimum and maximum temperature and precipitation data from ten stations for the period (19862019) were obtained from Ethiopian National Meteorological Agency (NMA). The max and min temperature were used to generate the potential evapo-transpiration data of each respective station. Initially, we collected max and min temperature and precipitation data from 18 stations found in the study area. We only used the ten stations (Table 1) which were better in their record length and missing values. The remaining stations were not selected because of their missing value and shorter record period. The selected stations are spatially well distributed across the study area (Fig. 1).

\section{Drought indices}

In order to understand the complexity of droughts, meteorologists and climatologists around the world developed and used numerous operational drought indices to characterize and monitor the intensity, duration and frequency of drought (WMO 2016; Dai 2011). Most of these indices use the records of precipitation, temperature and evapotranspiration (Steinemann et al. 2005). Palmer Drought Severity Index (PDSI) (Palmer 1965), the Percent of Normal, and the Deciles approach (Gibbs and Maher 1967), the Standard Precipitation Index (SPI) (McKee et al. 1993), Stream flow Drought Index (SDI) and Reconnaissance Drought Index (RDI) (Tsakiris and Vangelis 2005; Tsakiris et al. 2007b) are 
Table 1 Lists of Meteorological stations used in the study

\begin{tabular}{llllll}
\hline Station name & Latitude & Longitude & Altitude $(\mathrm{m})$ & Period of observation & No of years with Missing value \\
\hline Kulumsa & $8^{\circ} 01^{\prime} 10^{\prime \prime}$ & $39^{\circ} 09^{\prime} 45^{\prime \prime}$ & 2211 & $1987-2018$ & 2 \\
Melkassa & $8^{\circ} 23^{\prime} 54^{\prime \prime}$ & $39^{\circ} 19^{\prime} 58^{\prime \prime}$ & 1540 & $1987-2014$ & - \\
Ziway & $7^{\circ} 55^{\prime} 58^{\prime \prime}$ & $38^{\circ} 43^{\prime} 00^{\prime \prime}$ & 1640 & $1986-2019$ & - \\
Arsi Negelle & $7^{\circ} 21^{\prime} 05^{\prime \prime}$ & $38^{\circ} 40^{\prime} 19^{\prime \prime}$ & 1913 & $1988-2019$ & 5 \\
Wondo Genet & $7^{\circ} 06^{\prime} 07^{\prime \prime}$ & $38^{\circ} 37^{\prime} 35^{\prime \prime}$ & 1742 & $1986-2019$ & - \\
Hawassa & $7^{\circ} 03^{\prime} 53^{\prime \prime}$ & $38^{\circ} 28^{\prime} 59^{\prime \prime}$ & 1694 & $1986-2019$ & - \\
Butajira & $8^{\circ} 06^{\prime} 56^{\prime \prime}$ & $38^{\circ} 22^{\prime} 45^{\prime \prime}$ & 2000 & $1986-2019$ & - \\
Halaba & $7^{\circ} 18^{\prime} 43^{\prime \prime}$ & $38^{\circ} 05^{\prime} 21^{\prime \prime}$ & 1772 & $1986-2019$ & - \\
Wolaita Sodo & $6^{\circ} 50^{\prime} 00^{\prime \prime}$ & $37^{\circ} 43^{\prime} 00^{\prime \prime}$ & 1854 & $1986-2019$ & - \\
Arbaminch & $6^{\circ} 03^{\prime} 56^{\prime \prime}$ & $37^{\circ} 33^{\prime} 39^{\prime \prime}$ & 1227 & $1986-2019$ & - \\
\hline
\end{tabular}

some of the indices widely used for drought analysis. The most important thing which should be considered in selecting the index is the availability and quality of the input data, simplicity of its calculation, and its ability to consistently detect spatial and temporal variations of a drought event (Morid et al. 2006; Keyantash and Dracup 2002).

Understanding the strength and weakness of each index is crucial before deciding to apply. For example, PDSI is considered as important tool in monitoring drought at larger scale (Steinemann et al. 2005). It uses water balance models which require large amount of climate and soil moisture data (Mpelasoka et al. 2008; Ellis et al. 2010) which in turn leads to difficulty in its computation (Degefu and Bewket 2014; Morid et al. 2006). SPI is also a well known indices used for analysing meteorological droughts using only precipitation as an input (El Kenawy et al. 2016; Degefu and Bewket 2014; Viste et al. 2012). However, in arid areas where temperature is highest, it is vital to consider potential evapotranspiration to calculate drought. This study is conducted in lakes' region of Ethiopian Rift Valley where high temperature has profound implication on the use and consumption of water resource. Therefore, it is equally important to calculate potential evapotranspiration (PET) of the study stations in order to calculate meteorological drought. Hence, Reconnaissance Drought Index (RDI) which requires precipitation and PET as an input is used for drought severity assessments in this study.

\section{RDI computation}

The RDI was developed to approach the water deficit in a more accurate way, as a sort of balance between input and output in a water system (Tsakiris and Vangelis 2005; Tsakiris et al. 2007b). It is based both on cumulative precipitation $(\mathrm{P})$ and potential evapotranspiration (PET). Due to the unavailability of PET records, DrinC software is used for estimating the variable using Hargreaves method.

This software package was developed for providing a simple, though adaptable interface for the calculation of drought indices (RDI, SPI, SDI). The application of DrinC in several locations, especially in arid and semiarid regions, is gaining ground as a useful research and operational tool for drought analysis (Asadi Zarch et al. 2011; Tigkas et al. 2012).

In this study, RDI values were computed for each month of the year using DrinC (Drought Indices Calculator) software developed at the Centre for the Assessment of Natural Hazards and Proactive Planning and the Laboratory of Reclamation Works and Water Resources Management of the National Technical University of Athens (available at http://drinc.ewra.net/).

RDI was designed to quantify the precipitation deficit for multiple timescales. Although RDI can be calculated from 3 month up to 12 months (Tsakiris et al. 2007b), this study computed the RDI values at two time-scales, i.e. 3 months (RDI-3) and 12 months or annual (RDI-12). The RDI-3 was used to assess droughts during spring (locally known as Belg) and summer (locally Kiremt) seasons which represent the shorter and longer rain seasons respectively and RDI-12 was used to assess the annual drought. Positive RDI values indicate greater than mean precipitation and negative values indicate less than mean precipitation. Positive values of $\mathrm{RDI}_{\text {st }}$ indicate wet periods, while negative values indicate dry periods compared with the normal conditions of the area. According to Tigkas et al. (2015), RDI categorized drought severity in to mild, moderate, severe and extreme classes, with corresponding boundary values of $\mathrm{RDI}_{\text {st }}(-0.5$ to -1.0$),(-1.0$ to -1.5$),(-1.5$ to -2.0$)$ and $(<-2.0)$, respectively.

The RDI can be formulated in alpha $\left(\mathrm{RDI}_{\alpha \mathrm{k}}\right)$, normalized $\left(\mathrm{RDI}_{\mathrm{n}}\right)$ and standardized $\left(\mathrm{RDI}_{\mathrm{st}}\right)$ forms. The $\mathrm{RDI}_{\mathrm{st}}$ is used for drought severity evaluation, whereas $\mathrm{RDI}_{\alpha k}$ 
can be applied for assessing the aridity index. Basically, two expressions need to be evaluated viz., initial $\alpha \mathrm{k}$ and standardized RDI, i.e. $\mathrm{RDI}_{\mathrm{st}(\mathrm{k})}$. The initial $\mathrm{RDI}_{\alpha \mathrm{k}}$ for year $\mathrm{i}$ and reference period of $\mathrm{k}$ (months) is computed using a monthly time step as described in Tigkas et al. (2015).

$$
\alpha \frac{(i)}{k}=\frac{\sum_{j=l}^{k} P_{i j}}{\sum_{j=l}^{k} P E T_{i j}}, i=\mathrm{l}(\mathrm{l}) \mathrm{N} \text { and } j=\mathrm{l}(1) k
$$

in which Pij and PETij are the precipitation and potential evapotranspiration of the $j$-th month of the $i$-th year and

$\mathrm{N}$ is the total number of years of the available data.

The standardized form of RDIst is computed by fitting a log-normal probability density function to the given frequency distribution of $\alpha \mathrm{k}$ (Tigkas, 2008). The expression for the Standardized RDI is given as:

$$
R D I_{s t}^{(i)}=\frac{y^{(i)}-\bar{y}}{\hat{\sigma}_{y}}
$$

in which $y(i)$ is the $\ln (\alpha k(i)), y$ is its arithmetic mean and $\sigma y$ is its standard deviation.

According to Tsakiris et al. (2008) and Asadi Zarch et al. (2011) it has been proved that the calculation of RDIst could be performed better by fitting the gamma probability density function (pdf) at the given frequency distribution of $\alpha \mathrm{k}$, following the procedure described below.

$$
g(x)=\frac{1}{\beta^{a} \Gamma(a)} x^{a-1} e^{-x} / \beta, \text { for } \mathrm{x}>0
$$

Where: $\alpha>0$, is a shape parameter; $\beta>0$, is a scale parameter; $x>0$, is the amount of precipitation and $\Gamma$ $(\alpha)$ is the gamma function, defined as:

$$
\Gamma(\alpha)=\int_{0}^{\alpha} y^{\alpha-1} e^{-y} d y
$$

Fitting of distribution to data requires the estimation of $\alpha$ and $\beta$ as follows:

$$
\begin{aligned}
a & =\frac{1}{4 A}\left(1+\sqrt{1+\frac{4 A}{3}}\right), \beta=\frac{\bar{x}}{a}, \text { where } A \\
& =\ln (\bar{x})-\frac{\sum \ln (x)}{n}
\end{aligned}
$$

For $\mathrm{n}$ observations, the resulting parameters were then used to find the cumulative probability of an observed precipitation event for the given month or any other time scale:

$$
G(x)=\int_{0}^{x} g(x) d x=\frac{1}{\beta^{\alpha} \Gamma(\alpha)} \int_{0}^{x} x^{\alpha-1} e^{-x / \beta} d x
$$

Since, the gamma function is undefined for $\mathrm{x}=0$ and a precipitation distribution may contain zeros, where the cumulative probability becomes:

$$
H(x)=q+(1-q) G(X)
$$

Where $\mathrm{q}$ is the probability of zero precipitation and $\mathrm{G}(\mathrm{x})$ is the cumulative probability of the incomplete gamma function. If $\mathrm{m}$ be the number of zeros in a $\alpha \mathrm{k}$ time scales, then q could be estimated by $\mathrm{m} / \mathrm{n}$.

Finally the cumulative probability $\mathrm{H}(\mathrm{x})$ is transformed to the standard normal distribution with mean zero and the variance of one (Abramovitz and Stegun, 1965), which is the value of RDIst (Tsakiris et al. 2008).

Figures 4, 5 and 6 present the intensity of drought in each year of the observation period. However, Table 2 presents the total number of drought months in each timescale during the entire observation period. Once the intensity of drought is known in each timescale in the entire observation period, we multiply it by the number of months each time scale covers (i.e multiply the number of intensity by 3 for spring and summer, by 12 for annual timescale) to obtain the total number of drought months in each timescale.

\section{Mapping spatial distribution of drought incidences}

The RDI values produced by DrinC software were used as an input to ArcGIS to generate drought severity maps for the study area at 3 and 12-month time scales. To assess the spatial extent of droughts in the study area, RDI time series values of each meteorological station were interpolated by Inverse Distance Weighted (IDW) method using the Spatial Analyst tool of ArcGIS. The IDW method gives better representation for interpolation of precipitation distribution over heterogeneous topographic terrain (Tagel et al. 2011) (Fig. 2).

\section{Trend analysis}

In order to detect the changes in the RDI time series, trend analysis is carried out using nonparametric Mann-Kendall trend test. The MannKendall test (Yue et al. 2002) is appropriate for this analysis, since it is distribution-free, can accommodate outliers, is more suitable for non-normal, incomplete, and missing data, which frequently occur 
Table 2 Magnitude and frequency of drought events for spring, summer and annual timescale

\begin{tabular}{|c|c|c|c|c|c|c|c|c|c|c|c|}
\hline \multirow[t]{2}{*}{ Seasons } & \multirow{2}{*}{$\begin{array}{l}\text { Drought } \\
\text { magnitude }\end{array}$} & \multicolumn{10}{|c|}{ Total number of drought months } \\
\hline & & Arbaminch & Arsi Negelle & Butajira & Halaba & Hawassa & Kulumsa & Melkassa & Woliata & Wondo Genet & Ziway \\
\hline \multirow[t]{5}{*}{ Spring } & Mild & 15 & 15 & 12 & 12 & 6 & 15 & 12 & 21 & 18 & 12 \\
\hline & Moderate & 6 & 6 & 6 & 6 & 12 & 6 & 12 & 9 & 9 & 15 \\
\hline & Severe & 9 & 12 & 3 & 9 & 3 & 6 & 3 & 0 & 3 & 6 \\
\hline & Extreme & 0 & 0 & 6 & 0 & 3 & 3 & 3 & 3 & 3 & 0 \\
\hline & Total & 30 & 33 & 27 & 27 & 24 & 30 & 30 & 33 & 33 & 33 \\
\hline \multirow[t]{5}{*}{ Summer } & Mild & 9 & 12 & 12 & 21 & 12 & 18 & 9 & 18 & 12 & 9 \\
\hline & Moderate & 6 & 12 & 3 & 6 & 18 & 0 & 6 & 6 & 9 & 9 \\
\hline & Severe & 3 & 9 & 3 & 0 & 3 & 6 & 0 & 3 & 3 & 3 \\
\hline & Extreme & 3 & 3 & 6 & 3 & 0 & 3 & 6 & 3 & 3 & 3 \\
\hline & Total & 21 & 36 & 24 & 30 & 33 & 27 & 27 & 30 & 27 & 24 \\
\hline \multirow[t]{5}{*}{ Annual } & Mild & 96 & 12 & 12 & 60 & 36 & 72 & 48 & 72 & 60 & 84 \\
\hline & Moderate & 24 & 48 & 12 & 48 & 36 & 48 & 36 & 12 & 36 & 36 \\
\hline & Severe & 24 & 36 & 0 & 0 & 12 & 0 & 12 & 0 & 12 & 36 \\
\hline & Extreme & 0 & 24 & 36 & 12 & 24 & 12 & 12 & 12 & 24 & 12 \\
\hline & Total & 144 & 120 & 60 & 120 & 108 & 132 & 108 & 96 & 132 & 168 \\
\hline
\end{tabular}

in hydro-meteorological studies. The standard Pvalues which will be obtained from it was based on an assumption of independence between observations The test was performed for three timescales according to the reference periods used in the calculation of drought indices.
The Mann-Kendall test statistic $S$ is calculated as follows:

$$
S=\sum_{\mathrm{k}=1}^{n-1} \sum_{j=k+1}^{n} \operatorname{sgn}\left(x_{j}-x_{k}\right)
$$

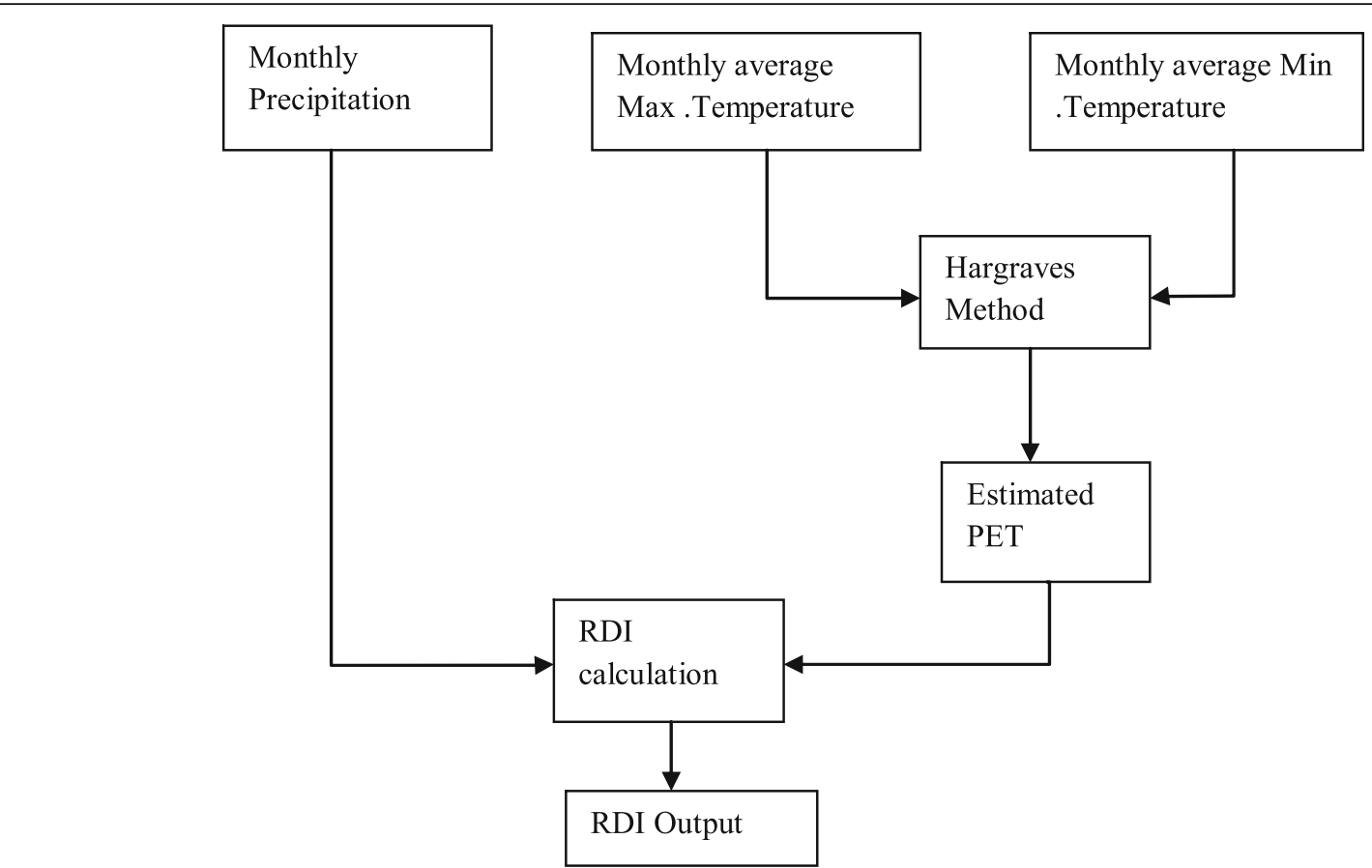

Fig. 2 The flow chart of DrinC software. Source: Adapted from Tigkas et al. 2015 
where $n$ is the length of the data set, $x_{j}$ and $x_{k}$ are the annual values in years $j$ and $k, j>k$, respectively, and

$$
\operatorname{sgn}\left(x_{j}-x_{k}\right)=\left[\begin{array}{cl}
1 & \text { if }\left(x_{j}-x_{k}\right)>0 \\
0 & \text { if }\left(x_{j}-x_{k}\right)=0 \\
-1 & \text { if }\left(x_{j}-x_{k}\right)<0
\end{array}\right]
$$

For samples greater than 10 the normal approximation test is used (Salmi et al. 2002). First the variance of $\mathrm{S}$ $\operatorname{Var}(\mathrm{S})$ is computed by the following equation that takes ties into account:

$$
=1 / 18\left[n(n-1)(2 n+5)-\sum_{p=1}^{q} t_{p}\left(t_{p}-1\right)\left(2 t_{p}+5\right)\right]
$$

Here $\mathrm{q}$ is the number of tied groups and tp is the number of data values in the pth group. The standardized test statistic $\mathrm{Z}$ was calculated using $\mathrm{S}$ and var.(s) values as follows:

$$
Z=\left[\begin{array}{ll}
s^{-1} / \sqrt{\operatorname{var}(s)} & \text { if }>0 \\
s+1 / \sqrt{\operatorname{var}(s)} & \text { if }<0 \\
0 & \text { if }=0
\end{array}\right]
$$

The value of $\mathrm{Z}$ in the Mann-Kendall test statistics follows standard normal distribution with average of 0 and variance of 1 . The presence of a statistically significant trend is evaluated using the $Z$ values. A positive value of $\mathrm{Z}$ indicates a rising trend and vice versa. In a two-tailed test for trend, the null hypothesis Ho (no trend) is rejected if the absolute value of $Z$ is greater than $Z 1-\alpha$ / 2 , where $Z 1-\alpha / 2$ is obtained from the standard normal cumulative distribution tables at $\alpha=0.001,0.01,0.05$ levels of significance. The computations were undertaken using the MAKESENS add-in software developed by the Finnish Meteorological Institute (Salmi et al. 2002).

\section{Results}

Magnitude and frequency of drought events

Lakes' region of Ethiopian rift valley (LRERV) experiences bi-modal rainfall (spring locally called belg and summer locally called kiremt) occurring between March to May and June to August respectively. In the study area, the average contribution of the belg and kiremt rain to the annual mean was $71 \%$ in the study period in which they contributed 28 and $43 \%$ to mean annual rainfall respectively. Our meteorological drought assessment therefore was for these two rainy seasons and for the annual timescales. Because, the rain-fed agriculture is strongly dependent on the bi-modal rain during these seasons in the study area and generally in the country (Viste et al. 2012; Funk et al. 2015; Tesfamariam et al. 2019). As a result, failure of rainfall in these growing seasons leads to drought incidences (Fig. 3).

The temporal and spatial characteristics of drought in LRERV were identified from RDI time series of multipletime steps. In this study, RDI for 3-months (belg and kiremt) and 12- months (annual) time steps are computed to examine the characteristics of drought in short and medium time periods. Drought happens every time when RDI is negative and its intensity comes to -0.5 or lower (Tsakiris et al. 2007a). Drought frequency, in this study, was measured by the number of years which experienced negative DRI values in the total time series. Varied drought magnitude classes were identified in 3and 12- months time scales across all stations in each year of the observation period (Figs. 4, 5 and 6) and total number of drought months in each timescales during the observation period (Table 2).

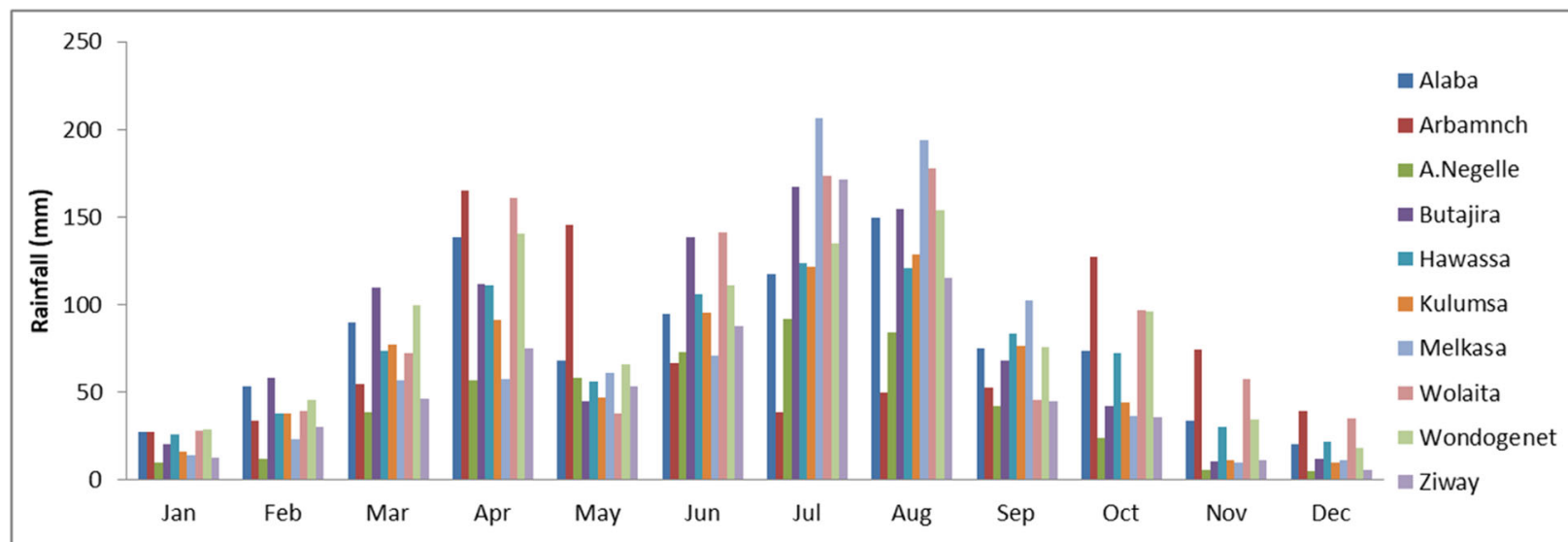

Fig. 3 Precipitation regime of the study stations 


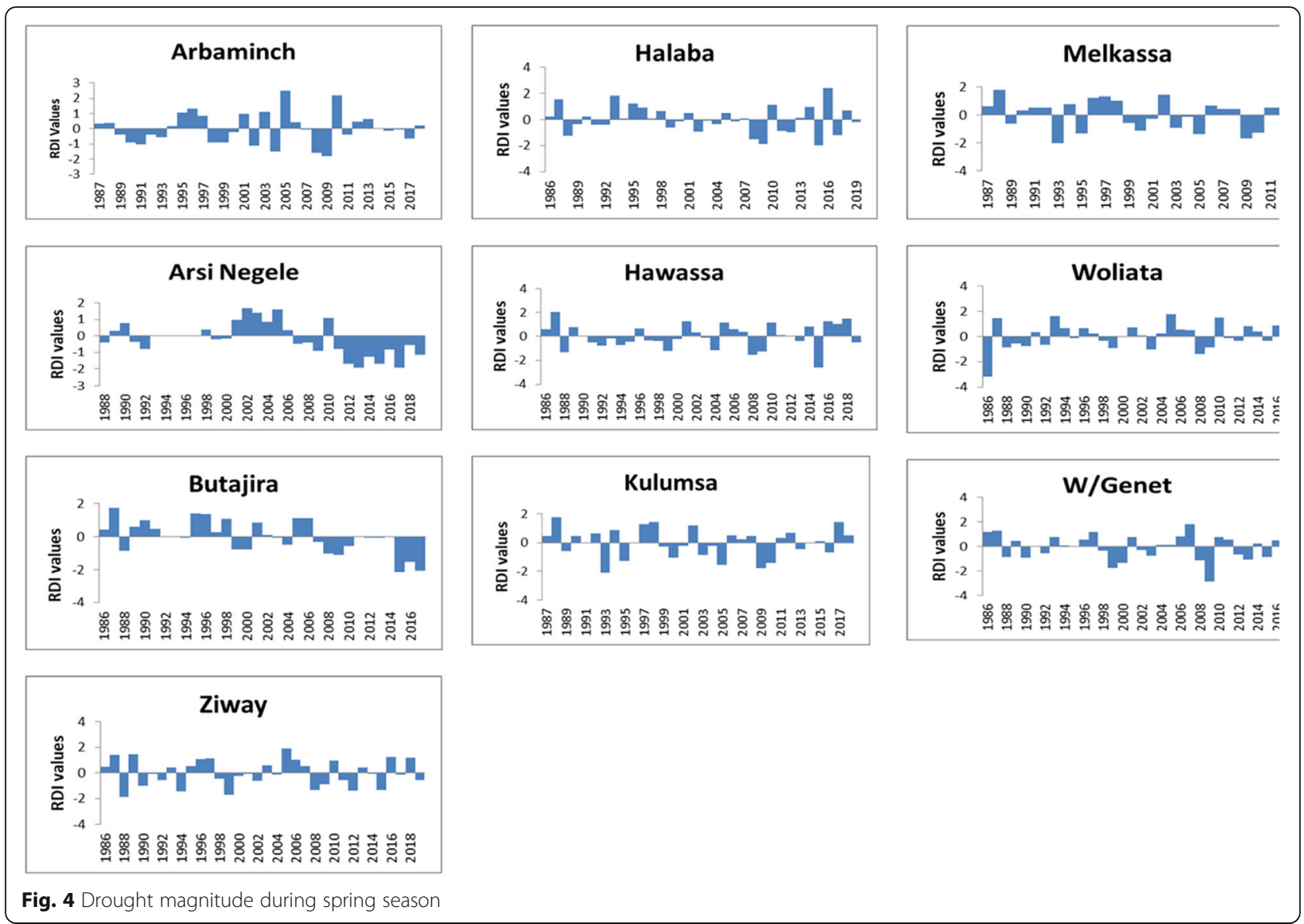

\section{Spring season}

The number of drought years with mild, moderate, severe and extreme severity classes computed at 3 month timescale in the study stations was varied (Fig. 4). The total number of drought years was highest in Arsi Negelle, Wolaita, Wondogenet and Ziway stations (Table 2). However, Butajira experienced two extreme droughts (RDI value of -2.05 and -2.14 ) and Hawassa, Kulumsa, Melkassa Wolaita and Wondogent stations experienced one extreme drought with the highest in Wolaita (-3.19) (Fig. 4). Although the magnitude was varied (Fig. 4), 1999 and 2009 were drought years across all studied stations. Arsi Negelle was experiencing negative RDI values since 2011 which indicates the consecutive occurrence of meteorological drought.

\section{Summer season}

The total number of drought months at 3 month timescale in the entire period of analysis was found between 21 and 36 months (Table 2). The total number of drought years was highest in Arsi Negelle station during summer season. Except Hawassa, all studied stations experienced extreme drought incidents during summer season. The year 2009, similar to spring season, was the driest year in all studied stations except Melkassa and Kulumsa (Fig. 5). The year 2015 was also a drought year of which seven out of ten stations had a negative RDI values ranging from -0.65 to -2.33 . Arbaminch, Wolaita and Ziway stations experienced an extreme drought event with RDI value of $-3.04,-3.52$ and -3.04 respectively (Fig. 5). The percentage of drought occurrences at this season was highest in Arsi Negelle (44\%) and Hawassa (40\%) (Fig. 5). This implies that the areas experienced a drought episode in every 2 to 3 years.

\section{Annual drought}

The total number of drought at annual timescale was highest at Arbaminch (144) and Ziway (168). The percentage of drought events at these two stations was $38 \%$ and $41 \%$ respectively. This indicates that these two areas experienced a drought episode in every 2 to 3 years. Except Arbaminch, all studied stations experienced extreme drought event at annual time scale. However its magnitude was extremely highest at Wolaita with RDI value of - 4.51. Moreover, three extreme droughts events were occurred for three consecutive years (2015-2017) with RDI value of $-2.12,-2.37$ and -2.86 at Butajira. The year 2015 was the worst drought year in the country of which six 


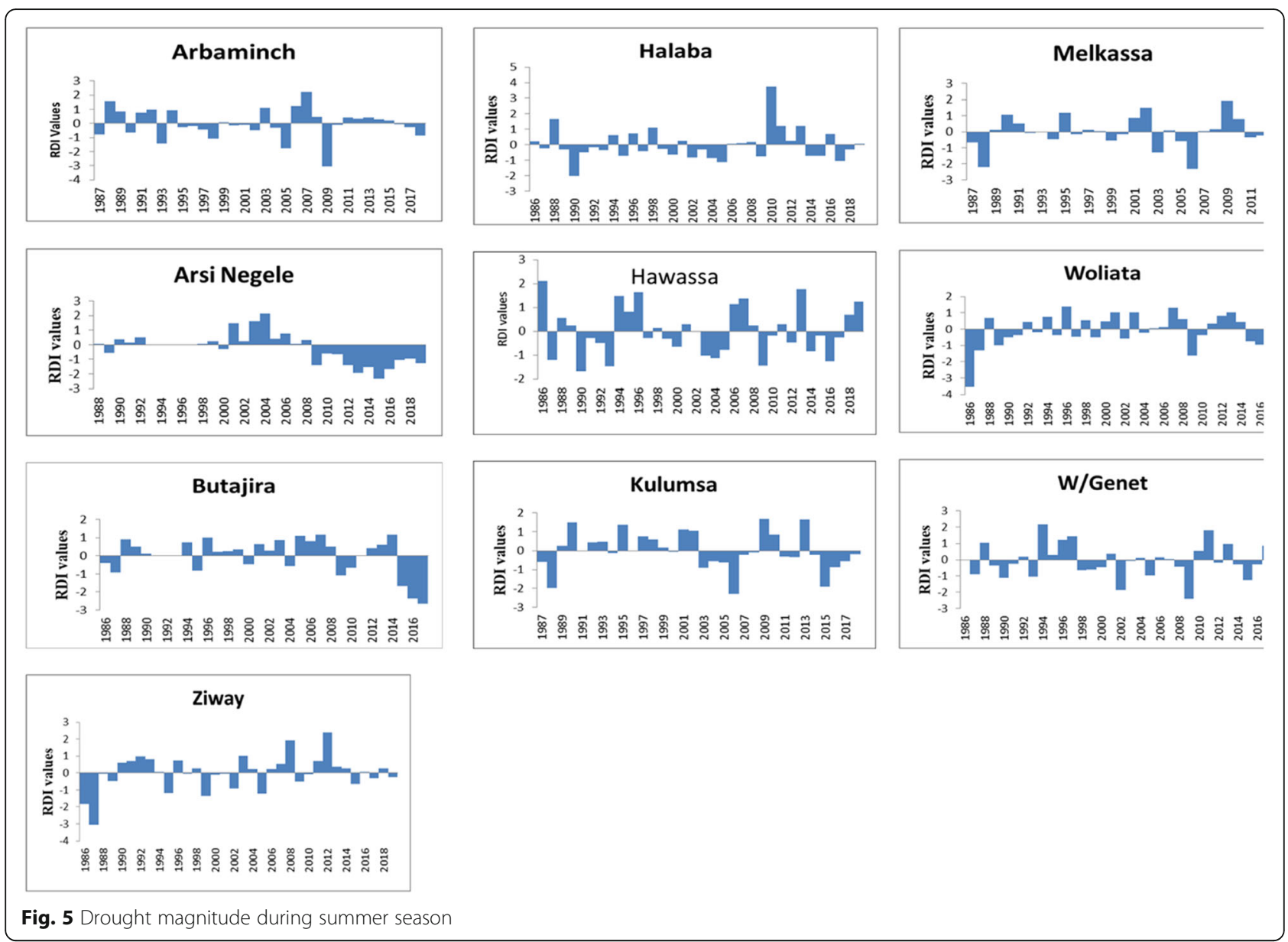

out of ten stations in the study area also showed extreme drought intensity (Fig. 6). From the total number of extreme drought events (14) registered in all stations in the entire study period (1987-2019), 11 extreme drought incidents were recorded from 2013 to 2017. This indicates that the magnitude of droughts has been increasing in the recent years. The year 2009 was a registered large-scale drought year which was common to the study area and other parts of the country. All stations except Melkassa and Kulumsa experienced drought events in 2009. Similarly, the year 1999, which was known for its dryness in all parts of the country, was also a drought year in six of the stations (Fig. 6). On average, the study area experienced at least moderate drought magnitude in every 2.45 years in the belg, 2.25 years in the kiremt seasons and 2.7 years interval at annual time scale during 1986-2019.

\section{Spatial distribution of drought occurrences}

Time series (1986-2019) of drought indices generated by employing the RDI procedure was used as an input to ArcMap/GIS to show the spatial extent of drought events in the study area at multiple time scales.
The spatial patterns of drought at different time steps (3and 12-months) were depicted in Figs. 7a-d, 8, 9 and 10a-c. The general patterns of drought events in the study region were interpolated based on RDI values of the ten stations under the study period. The frequencies of drought for different intensity classes and timescales show complex and localized patterns. During spring, the southern part of the study area was prone to mild drought intensity with the average $20 \%$ probability of drought occurrence. In the same season, large parts of the study area also experienced severe drought episodes (on average 3 during the study period). Typically, Arbaminch, Wolaita Sodo, Arsi Negelle (being the highest), Ziway and Kulumsa stations had severe drought event. During summer, there was no considerable spatial pattern of drought except the mild and moderate droughts events. Southern part of the study area (Arbaminch and Wolaita Sodo) and the middle stations had greater exposure to mild and moderate droughts respectively. At annual time scale, the central and northern parts of the study area experienced moderate drought (the highest in Arsi Negelle and Kulumsa). Generally, the total frequency of drought was highest in Arsi Negelle, Wolaita, Wondo Genet and Ziway in spring season. Whereas Arsi 


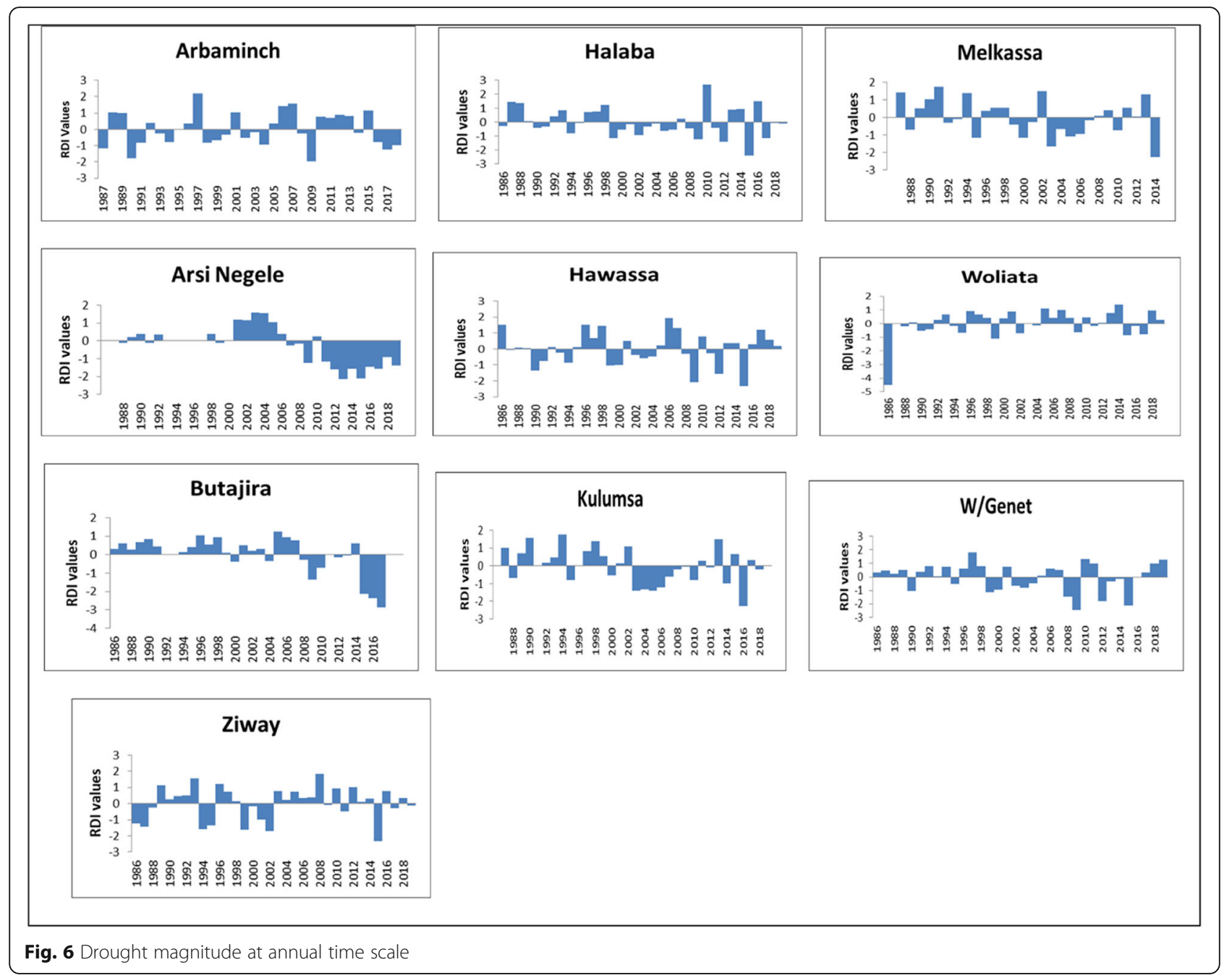

Negelle and Hawassa had highest number of drought events in summer. At the annual time scale, Ziway experienced the highest number of drought events.

\section{Trends of drought occurrences}

Trends of drought occurrences for 3- spring and summer and annual timescales were shown in Table 3.

The Mann-Kendall trend test during spring showed decreasing changes in RDI values in 6 out of 10 stations (Table 3). This indicates that drought incidence during spring showed an increasing tendency. However, significant increasing trend of drought occurrence was observed at Arsi Negelle and Butajira stations (Table 3). Similarly, the RDI values during summer showed increasing changes in most of the stations. However, significant increasing trend of drought was observed only at Arsi Negelle. Similar significant increasing trend of drought was also observed (annual) timescale at Arsi Negelle and Butajira stations. Although trends at all time-scales were not statistically significant, most of the stations (Table 3) showed increasing tendencies of drought event. Generally more meteorological droughts were observed during spring and annual timescales than summer (Table 3).

\section{Discussion}

In this study, we presented a brief drought analysis at annual and seasonal time steps using RDI. The study monitored the intensity, frequency, trend, spatial distribution of drought events over LRERV of Ethiopia during the experimental years of 1986 to 2019 at 3 - and 12-month time scales. As the study area experiences bimodal rainfall (spring and summer) (Tesfamariam et al. 2019) occurring between March to May and June to August respectively, we characterized RDI at three-month timescale for both seasons.

Results indicate that occurrences of drought in LRERV showed temporal variation. The highest number of drought events (168 months) was recorded in Ziway at 

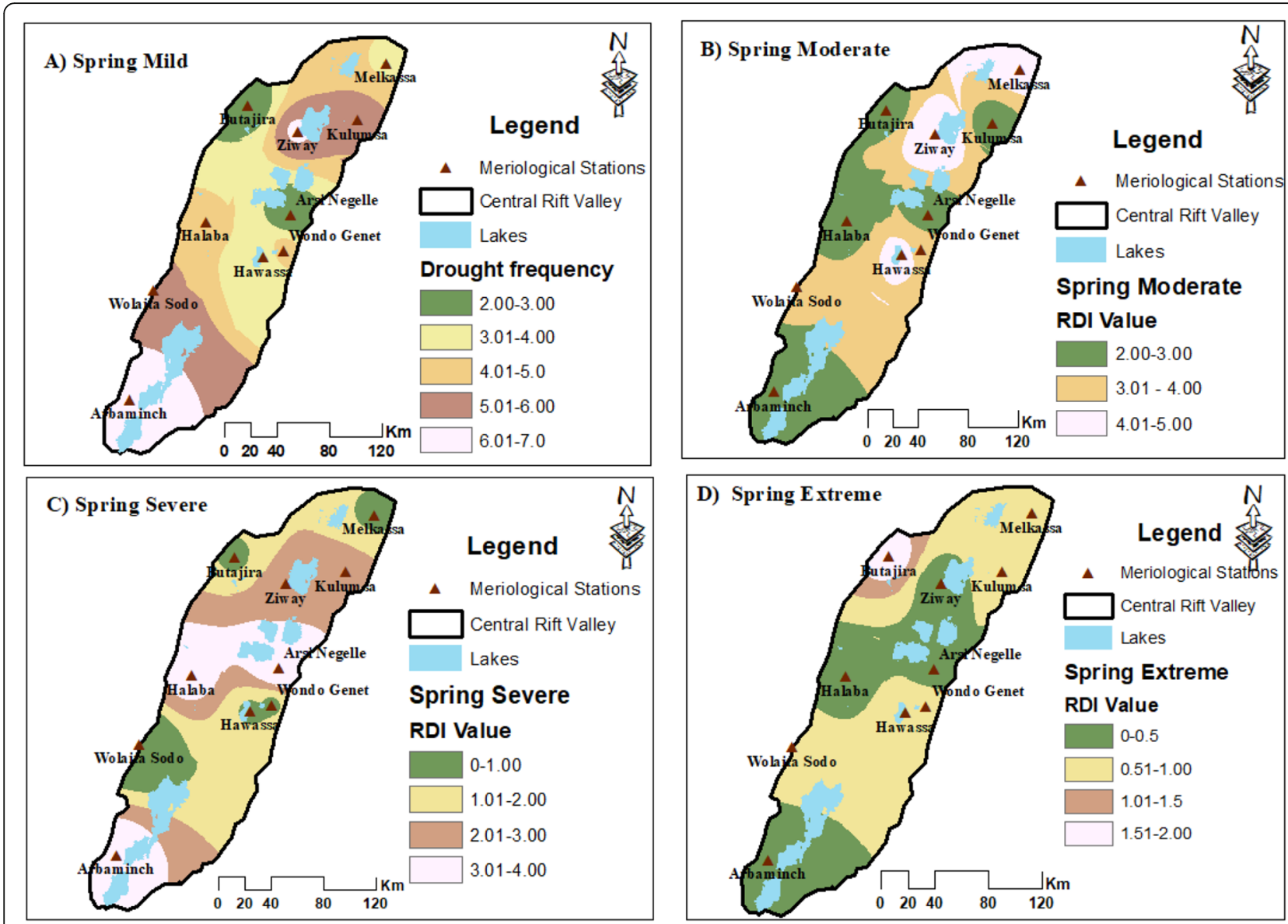

Fig. 7 Spatial distribution of drought frequency in spring season in LRERV of Ethiopia: a mild drought, $\mathbf{b}$ moderate drought, $\mathbf{c}$ severe drought, $\mathbf{d}$ extreme drought

annual timescale which accounts for $40 \%$ of the total number of months over the study period. However, during spring, all stations had comparable number of drought episodes ranging from 24 to 33 months (Table 2). There were more number of total drought events in summer season than spring at Halaba, Arsi Negelle and Hawassa. The total number of drought months during summer in Arsi Negelle, Hawassa and Halaba in the entire study period was 36,33 and 30 respectively (Table 2 ).

The prevalence of drought during summer (the main growing season) has multifaceted implications on crop and livestock production, surface hydrology and biodiversity of the study area (Mohammed et al. 2017). Failing to rain at this season means failure of $85-95 \%$ of the food crop which is produced in this season (Degefu 1987). Studies indicate that reduction of Ethiopian summer rainfall and the subsequent drought occurrence were highly associated with fluctuations in pressure gradient and sea surface temperature (SST) (Degefu and Bewket, 2017; Diro et al. 2011; Korecha and Barnston 2007; Haile 1988). The development of more warm areas in the equatorial Pacific Ocean attributed to an increase in local precipitation over that ocean and reduced rainfall over Eastern Africa, including Ethiopia (Funk et al. 2014). When El Nino prevails in the equatorial Pacific Ocean, the summer rainfall in the country in general declines to below average, causing drought events (Degefu and Bewket, 2017; Fekadu 2015). In contrast, La Nina events favor further temporal expansion of the summer rain beyond the normal seasonal period of a given area. The clear association between ENSO and the belg rain in Ethiopia was also reported in many studies. During La Nina, the main recipients of spring rain in the country experience shortage of rainfall while during El Nino situation, most of the spring rainfall recipients receive higher amount of rainfall (Tesfamariam et al. 2019; Fekadu 2015). Thus, the frequent drought incidence in the study area during spring and summer seasons could be primarily linked to La Nina and El Nino situations, respectively (Tesfamariam et al. 2019).

The findings indicate that the frequent drought episodes had varying intensities in the study area at all studied timescales. Extreme drought incidents were recorded in almost all stations at summer and annual 

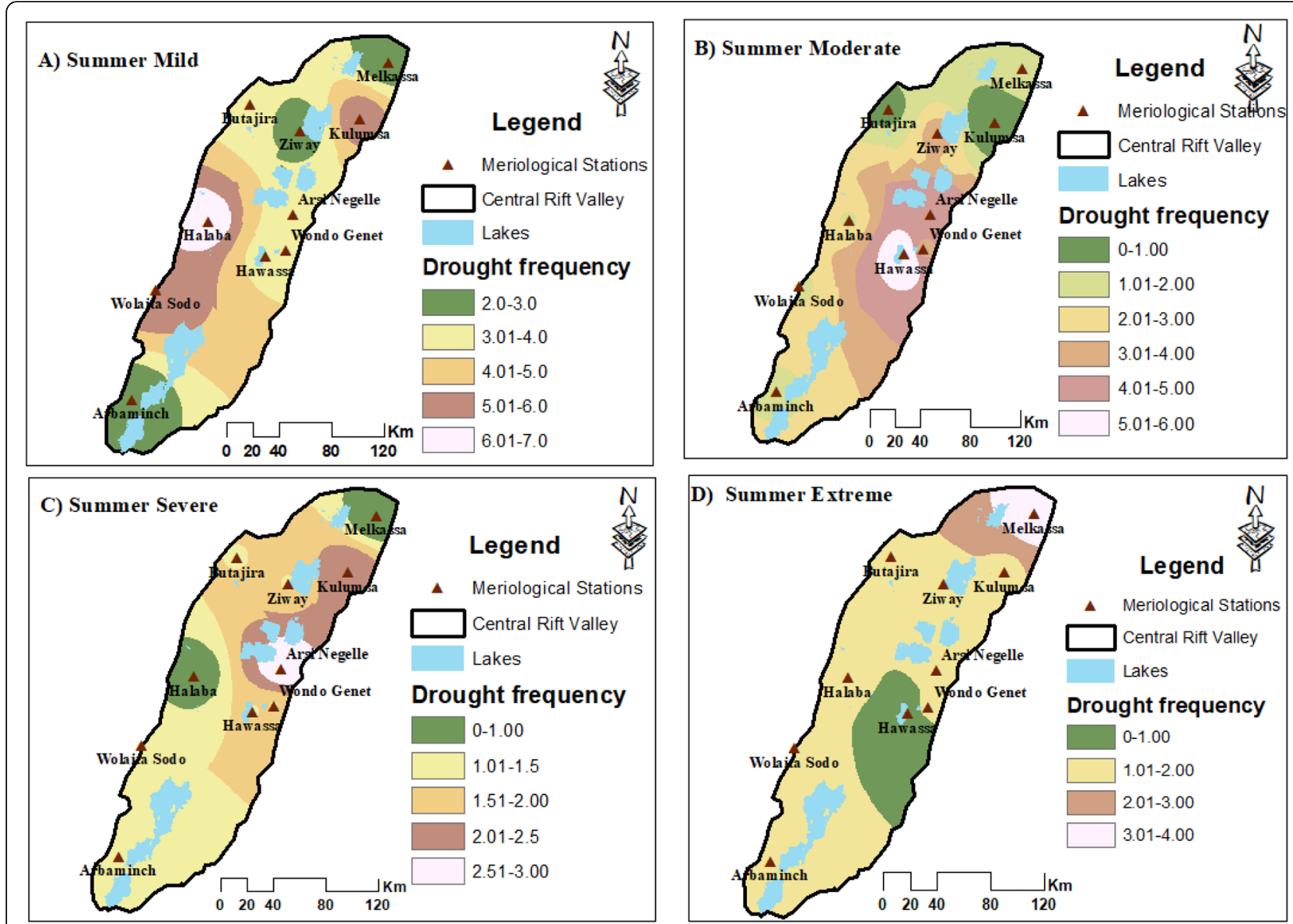

Fig. 8 Spatial patterns of drought events in summer season in LRERV of Ethiopia: a mild drought, $\mathbf{b}$ moderate drought, $\mathbf{c}$ severe drought, $\mathbf{d}$ extreme drought

timescale. A total of 33 extreme drought months were observed in all stations during summer with varying magnitude (-2.01 at Halaba to -3.52 at Wolaita) (Fig. 5). Compared to other stations, Butajira and Melkasa experienced more number of extreme drought months (6) in this season during the entire study period (Table 2). Similarly, a total of 168 extreme drought months were observed in all stations except Arbaminch at annual timescale with varying magnitude ranging from -2.10 at Hawassa to -4.51 at Wolaita (Fig. 6). The most remarkable condition at this timescale is that 156 out of 168 extreme drought months were recorded in recent years (2009 onwards) with the highest in Butajira (36 months). It is again striking that 60 out of 168 extreme drought months were recorded in 2015. This year was known for its dryness due to the existence of El Nino all over the country which brought significant impact by limiting agricultural production, straining livelihoods and exacerbating food insecurity among poor and vulnerable households (Mohammed et al. 2017; UN OCHA 2015).

The other most striking event was that the intensity of drought events observed in Wolaita in 1986 at all timescales (RDI value of $-3.19,-3.52$ and -4.51 for spring, summer and annual respectively) were very extraordinary and devastating. These had strong correlation with the occurrence of El Nino in 1986 in the country (FAO 2014). Similarly in 1986 most extreme drought incidence at Wolaita (with SPI <-4.02) at 3-months timescale was reported by Degefu et al., (2014) and Jufare (2008). The occurrence of extreme intensity droughts at 3-month have important implications on rainfed agriculture (Morid et al. 2006; Ellis et al. 2010). The 1986 rainfall variability and drought have caused significant adverse effects on crop production and subsequent food shortages in the most densely populated areas, particularly in the Wolaita Zone (Jufare 2008). The result implies that drought magnitude can vary largely over space and this exceptional extreme drought shows a local character, where small area was affected, while others had less severe drought magnitude or even no drought. This finding is supported by the study of El Kenawy et al. (2016) who found similar drought occurrences in studying the changes in the frequency and severity of hydrological droughts over Ethiopia from 1960 to 2013. It is well known that the 

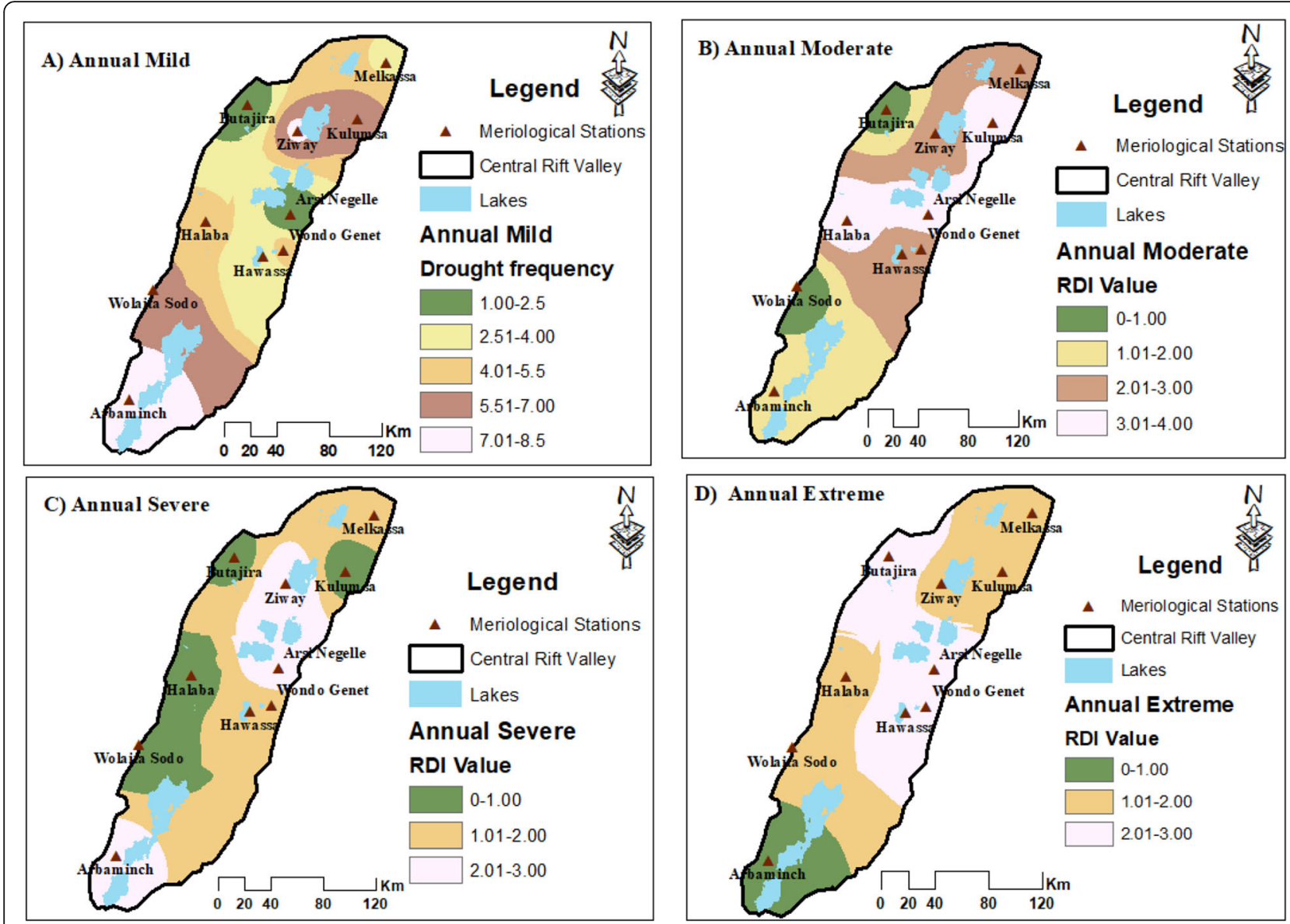

Fig. 9 Spatial distribution of drought events at annual time scale in LRERV of Ethiopia: a mild drought, $\mathbf{b}$ moderate drought, $\mathbf{c}$ severe drought, $\mathbf{d}$ extreme drought

complex terrain regulates the Ethiopian climate by creating numerous microclimates having different amounts of rainfall (Viste et al., 2013; Jury 2010; Dinku et al. 2007; Degefu 1987).

The frequency of drought incidence became intense in the study area from 2008 onwards at all timescales compared to the 1990s and 2000s. Arsi Negelle, for example, experienced all drought incidences (189) which constituted $38 \%$ of the total number of months at all timescale from 2009 onwards. The year 2009 was one of the few years with drought conditions in all of Ethiopia, both on seasonal and annual scales. On the national level, 2009 was the second driest year in history after 1984 (Viste et al. 2012). Although drought conditions prevailed in all parts of Ethiopia in 1984 and 2009 on both seasonal and annual time scales, the droughts were of a more localized or regional character, affecting only some parts of the country. The increasing tendency of drought in recent years might be the manifestation of borderless global warming. Generally, droughts became more frequent on shorter time scales but their duration was short.
The opposite is true for longer time scales. Their frequency became less but remained for longer time.

Trends of drought events at 3- and 12-month timescales over the study period were depicted in Table 3 . Negative RDI values in the MK test indicates the increasing tendency of drought and vice versa. The MK test results indicate that RDI values were ranging from 0.13 to $-0.69 \mathrm{Z}$ unit per decade at the three-month (spring) timescales suggesting increasing tendency of drought episodes. Similarly, at annual timescale, the RDI values were ranging from 0.17 to -0.73 unit per decade. The trend of drought incidence was significantly increasing in Arsi Negelle at all timescales especially pronounced in recent years and Butajira in spring and annual timescales. The increasing trends of droughts episodes at the two stations were pronounced in recent 10 years which has strong association with global warming.

The spatial patterns of drought events showed more localized distribution and variability when we considered intensity classes and timescales. For example, more frequent mild intensity drought events were observed in the central parts and south western part of the study 

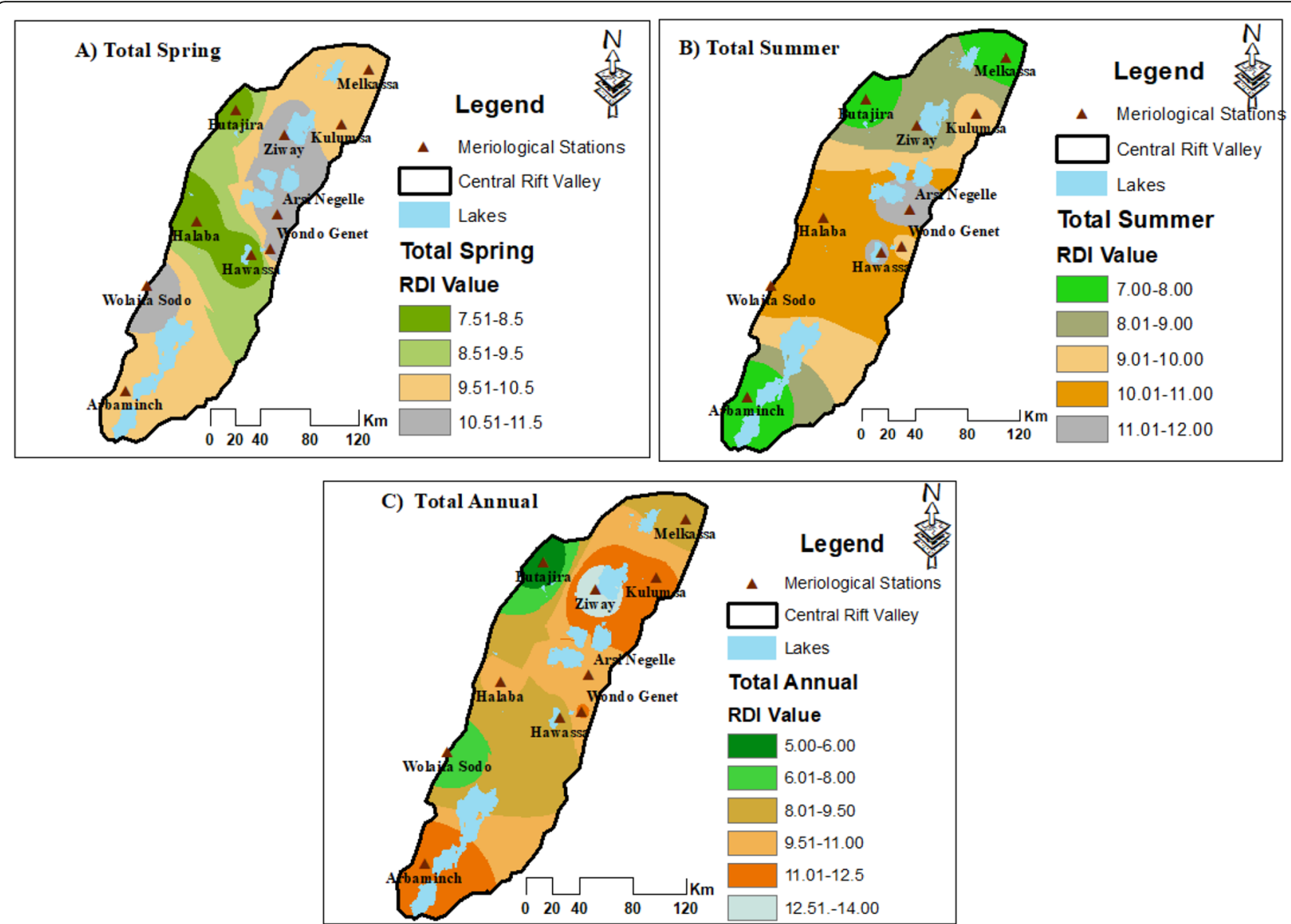

Fig. 10 Spatial distribution of total drought events in spring and summer seasons and at annual timescale in Lake's region of Ethiopian rift valley. a) Total drought in spring. b) Total drought in summer. c) Total annual drought

area during spring. The northern parts of the study area experienced more extreme drought events during spring season. More number of mild droughts was observed in north eastern and south western parts of the study area

Table 3 The Mann-Kendall's trend test for spring, summer and annual time scales

\begin{tabular}{lllll}
\hline \multicolumn{2}{l}{ Season } & RDI 3 Spring & RDI 3 Summer & RDI 12 months \\
\cline { 1 - 3 } $\mathbf{S / N}$ & Station Name & MK test & MK test & MK test \\
\hline $\mathbf{1}$ & Halaba & -0.95 & -0.03 & -1.19 \\
$\mathbf{2}$ & Arbaminch & 0.11 & -0.28 & 0.31 \\
$\mathbf{3}$ & Arsi Negele & $-2.84^{* *}$ & $-2.96^{* *}$ & $-3.00^{* *}$ \\
$\mathbf{4}$ & Butajira & $-3.06^{* *}$ & -0.36 & $-2.76^{* *}$ \\
$\mathbf{5}$ & Hawassa & 0.74 & 0.06 & 0.36 \\
$\mathbf{6}$ & Kulumsa & -0.18 & -1.14 & -1.64 \\
$\mathbf{7}$ & Melkasa & -0.97 & 0.26 & -1.21 \\
$\mathbf{8}$ & Wolaita & 0.65 & 1.60 & 1.33 \\
$\mathbf{9}$ & Wondogenet & 0.12 & 0.77 & -0.24 \\
$\mathbf{1 0}$ & Ziway & -0.03 & 0.65 & 0.30 \\
\hline
\end{tabular}

Note: ** indicate trends of drought incidence significant at $p<0.01$ during summer. Moderate drought events were more pronounced at east central part of the study area especially around Arsi Negelle and Hawassa at summer time scale. Except few pocket areas around Hawassa, all areas of the study area had substantial number of extreme intensity of drought during summer. However, except the southern part of the study area, the numbers of extreme drought incidents were pronounced all over the study area at annual timescale.

\section{Conclusions}

This study focused in evaluating the intensity, frequency, trend and spatial patterns of meteorological drought in the LRERV based on rainfall and calculated PET data from ten stations for the period 1986-2019. The study employed RDI to generate drought indices at 3 and 12months timescale. Mann-Kendall trend test was also used to detect trends of change.

Even though almost all stations in the study area were suffering from drought, the temporal distribution and frequency of droughts varied markedly among each station. Although the intensity of drought varied, all 
stations experienced frequent drought incidences in recent years (2009 onwards) at all timescales. All areas in LRERV were stricken at least partially by the historical drought events but with varying frequency and intensity. It was evident that most of the stations were exposed to severe and extreme droughts at all timescales in the most known national driest years of 2009 and 2015. Generally, more frequent droughts were observed in the study area compared to the nationally documented historical drought events, which implies higher vulnerability of LRERV to climate variability.

The frequency and intensity of drought events computed at all timescales show complex and localized spatial patterns. However, the total frequency of droughts for all timescales showed that the southern and north eastern part of LRERV experienced the most recurrent drought risks during the study period. Although drought incidents were less frequent at Wolaita Sodo compared to Arsi Negelle and Ziway, the area has experienced the most extreme drought in all time scales reaching to RDI value of -4.51 and caused significant adverse effects on crop production and subsequent food shortages in the most densely populated areas.

The Mann-Kendall trend test at all timescales indicates the tendency of increasing drought in most of the stations. However, the drought incidents were significantly increasing at Arsi Negelle at all timescales and Butajira at spring and annual timescale. The existence and occurrence of such localized droughts in LRERV suggest differences in local and regional scale rainforming factors in the region. However, this requires a further study, which should consider how local factors (topography, forest, land cover change, water bodies, etc.) affect rainfall amounts in LRERV. Generally, the implication of this study is that drought events and their negative effects are highly localized in the study area and there is a need for local-scale planning for drought management and response. Local climate studies, such as the present study, should be strengthened since they are useful to provide fine scale climate information for drought risk management and adaptation purposes.

\section{Abbreviations \\ LRERV: Lakes' region of Ethiopian rift valley; IPCC: Intergovernmental Panel on Climate Change; CRED: Center for Research on the epidomology of Disaster; NMA: National Meteorological Agency; PET: Potential evapotranspiration; MK: Mann Kendall; PdSI: Palmer Drought Severity Index; SPI: Standard Precipitation Index; RDI: Reconnaissance Drought Index; ENSO: El Nino and the southern oscillation}

\section{Acknowledgments}

We are very grateful to the Ethiopian National Meteorological Agency (NMA) for providing us the monthly rainfall and maximum and minimum temperature data used for this study free of charge. We also thank Dilla University for financial support to both authors.

\section{Authors' contributions}

YM was responsible for all activities of the research process such as the design, data compilation and entry, data analysis, and interpretation of results as well as writing up of the manuscript. AY was also involved in improving the quality of manuscript by providing constructive guidance, critical comments and suggestions on the study design, data analysis and interpretation. Both authors read and approved the final manuscript.

\section{Funding}

This study was financially supported by Dilla University.

\section{Availability of data and materials}

The datasets used and/or analysed during the current study are available from the corresponding author on reasonable request.

\section{Declarations}

\section{Competing interests}

The authors declare that they have no conflict of interests.

Received: 29 October 2020 Accepted: 20 April 2021

Published online: 31 May 2021

\section{References}

Abramovitz M, Stegun I (1965) Handbook of mathematical functions. National bureau of standards, applied mathematics series-55, Washington, D.C

Asadi Zarch MA, Malekinezhad H, Mobin MH, Dastorani MT, Kousari MR (2011) Drought monitoring by reconnaissance drought index (RDI) in Iran. Water Resour Manag 25(13):3485-3504. https://doi.org/10.1007/s11269-011-9867-1

Cochrane L, Tamiru Y (2016) Ethiopia's productive safety net programme: power, politics and practice. J Int Dev 28:649-665. https://doi.org/10.1002/jid.3234

CRED and UNISDR (2015) The human cost of weather related disasters: 19952015. Centre for Research on the Epidemiology of Disasters, Brussels, p 30

Dai A (2011) Drought under global warming: a review. Wiley Interdiscip Rev Clim Chang 2(1):45-65. https://doi.org/10.1002/wcc.81

Degefu MA, Bewket W (2014) Trends and spatial patterns of drought incidence in the omo ghibe river basin, Ethiopia. Geografiska Annaler A Phys Geogr. https://doi.org/10.1111/geoa.12080

Degefu W (1987) Some aspects of meteorological drought in Ethiopia. In: Glantz MH (ed) Drought and hunger in Africa: denying famine a future. Press Syndicate of the University of Cambridge, Cambridge, pp 223-236

Dinku T, Ceccato P, Grover-Kopec E, Lemma M, Connor SJ, Ropelewski CF (2007) Validation of satellite rainfall products over East Africa's complex topography. Int J Remote Sens 28(7):1503-1526. https://doi.org/10.1080/01431160600954 688

Diro GT, Grimes DIF, Black E (2011) Large scale features affecting Ethiopian rainfall. In: Williams CJR, Kniveton DR (eds) African climate and climate change, vol 43. Advances in global change researchSpringer, Netherlands, pp 13-50. https://doi.org/10.1007/978-90-481-3842-5_2

Edossa DC, Babel MS, Gupta AD (2010) Drought analysis in the Awash river basin Ethiopia. Water Resour Manag. 24:1441-1460. https://doi.org/10.1007/s11269009-9508-0

El Kenawy AM, McCabe MF, Vicente-Serrano SM, López-Moreno Jl, Robaa SM (2016) Changes in the frequency and severity of hydrological droughts over Ethiopia from 1960 to 2013. Cuadernos De Investigación Geográfica 42(2). https://doi.org/10.18172/cig.2925

Ellis AW, Goodrich GB, Garfin GM (2010) A hydroclimatic index for examining patterns ofdrought in the Colorado river basin. Int J Climatol 30(2):236-255. https://doi.org/10.1002/joc.1882

FAO (2014) Understanding the drought impact of El Niño on the global agricultural areas: an assessment using FAO's agricultural stress index (ASI) ISBN 978-92-5-108671-1

Fekadu K (2015) Ethiopian seasonal rainfall variability and prediction using canonical correlation analysis (CCA). Earth Sci 4(3):112-119. https://doi.org/1 0.11648/j.earth.20150403.14

Funk $C$ et al (2014) A quasi-global precipitation time series for drought monitoring. US Geol Surv Data 832:4. https://doi.org/10.3133/ds832

Funk C et al (2015) The climate hazards infrared precipitation with stations-a new environmental record for monitoring extremes. Sci Data 2:150066. https://doi.org/10.1038/sdata.2015.66 
Gebrehiwot T, van der Veena A, Maathuis B (2011) Spatial and temporal assessment of drought in the Northern highlands of Ethiopia. Int J Appl Earth Obs Geoinf. 13:309-321

Gibbs WJ, Maher JV (1967) Rainfall deciles as drought indicators, Bureau of Meteorology, bulletin no. 48, Melbourne

Gizachew, Shimelis (2014) Analysis and mapping of climate change risk and vulnerability in central rift valley of Ethiopia. Afr Crop Sci J 22(Issue Supplement s4):807-818

Haile T (1988) Causes and characters of drought in Ethiopia. Ethiopian J Agric Sci 10:1-2 8-597

IPCC II (2014) "Climate change 2014; impacts, adaptations and vulnerability", working group II

Jufare AT (2008) Livelihood adaptation, risks and vulnerability in rural Wolaita, Ethiopia. PhD diss., Department of International Environment and Development Studies, Noragric Norwegian University of life science, UMB

Jury MR (2010) Ethiopian decadal climate variability. Theor Appl Climatol 101:2940. https://doi.org/10.1007/s00704-009-0200-3

Keyantash J, Dracup J (2002) The quantification of drought: an evaluation of drought indices. Bull Am Meteorol Soc 83(8):1167-1180. https://doi.org/10.11 75/1520-0477-83.8.1167

Korecha D, Barnston AG (2007) Predictability of June-September rainfall in Ethiopia. Mon Weather Rev 135(2):628-650. https://doi.org/10.1175/MWR33 04.1

Legesse D, Vallet-Coulomb C, Gasse F (2004) Analysis of the hydrological response of a tropical terminal Lake, lake Abiyata (Main Ethiopian Rift Valley) to changes in climate and human activities. Hydrol Process 18(3):487-504. https://doi.org/10.1002/hyp.1334

Makin MJ, Kingham TJ, Waddams AE, Birchall CJ, Teferra T (1975) Development, and prospects in the southern Rift Valley, Ethiopia. Land resource study no. 21, land resources division, UK, min. Overseas development, Tolworth, UK

McKee T.B., Doesken N.J. and Kleist J. (1993) "The relationship of drought frequency and duration to time scales", eighth conference on applied climatology, American Meteorological Society, Anaheim, CA, 17-22 January, pp. 179-184

Mohammed Y, Yimer F, Tadesse M, Tesfaye K (2017) Meteorological drought assessment in north east highlands of Ethiopia. Int J Climate Change Strateg Manage 10(1):142-160. https://doi.org/10.1108/IJCCSM-12-2016-0179

Morid S, Smakhtinb V, Moghaddasi M (2006) Comparison of seven meteorological indices fordrought monitoring in Iran. Int J Climatol 26(7): 971-985. https://doi.org/10.1002/joc.1264

Mpelasoka F, Hennessy K, Jones R, Bates B (2008) Comparison of suitable drought indices for climate change impacts assessment over Australia towards resource management. Int J Climatol 28(10):1283-1292. https://doi.org/10.1 002/joc. 1649

Muluneh A, Bewket W, Keesstra S, Stroosnijder L (2016) Searching for evidence of changes in extreme precipitation indices in the central Rift Valley of Ethiopia. Theor Appl Climatol. https://doi.org/10.1007/s00704-016-1739-4

Muluneh A, Biazin B, Stroosnijder L, Bewket W, Keesstra S (2014) Impact of predicted changes in precipitation and atmospheric carbondioxide on maize and wheat yields in the central rift Valleyof Ethiopia. Reg Environ Chang 15(6):1105-1119. https://doi.org/10.1007/s10113-014-0685-x

Musein BS (2006) Remote sensing \& GIS for land cover/land use change detection and analysis in the semi-natural ecosystems and agriculture landscapes of the central Ethiopian Rift Valley. PhD dissertation, Technology University of Dresden, Germany

Palmer WC (1965) "Meteorological droughts", U.S. Department of Commerce weather bureau research paper 45, p 58

Salmi T., Määttä A., Anttila P., Ruoho-Airola T. and Amnell T., (2002) Detecting trends of annual values of atmospheric pollutants by the Mann-Kendall test and Sen's slope estimates: the excel template application MAKESENS. Finnish Meteorological Institute, No. 31

Steinemann AC, Hayes MJ, Cavalcanti LFN (2005) Drought indicators and triggers. In: Wilhite DA (ed) Drought and water crises: science, technology, and management issues, CRC press

Tagel G, Veen AVD, Maathuis B (2011) Spatial and temporal assessment of drought in the northern highlands of Ethiopia. Int J Appl Earth Obs Geoinf 13:309-321

Tesfamariam B, Gessese B, Melgani F (2019) Characterizing the spatiotemporal distribution of meteorological drought as a response to climate variability: the case of rift valley lakes basin of Ethiopia. Weather Climate Extremes 26: 100237. https://doi.org/10.1016/j.wace.2019.100237
Teshome A, Zhang J (2019) Increase of extreme drought over Ethiopia under climate warming. Hindawi Adv Meteorol 2019(Article ID 5235429):18. https:// doi.org/10.1155/2019/5235429

Tigkas D (2008) Drought characterisation and monitoring in regions of Greece. Eur Water 23/24:29-39

Tigkas D, Vangelis H, Tsakiris G (2012) Drought and climatic change impact on stream flow in small watersheds. Sci Total Environ 440:33e41

Tigkas D, Vangelis H, Tsakiris G (2015) DrinC: a software for drought analysis based on drought indices. Earth Sci Inf 8(3):697e709

Tsakiris G, Loukas A, Pangalou D, Vangelis H, Tigkas D, Rossi G, Cancelliere A (2007a) Drought characterization. In: Iglesias A et al (eds) Drought management guidelines technical annex. CIHEAM / EC MEDAWater, Zaragoza, pp 85-102

Tsakiris G, Nalbantis I, Pangalou D, Tigkas D, Vangelis H (2008) Drought meteorological monitoring network design for the reconnaissance drought index (RDI). In: Franco Lopez A (ed) Proceedings of the 1st international conference "drought management: scientific and technological innovations". Zaragoza, Spain: option Méditerranéennes, series a, no. 80, 12-14 June 2008; 2008, pp 57-62

Tsakiris G, Pangalounad D, Vangelis H (2007b) A regional drought assessment based on the reconnaissance drought index (RDI). Water Resour Manag 21(5):821-833. https://doi.org/10.1007/s11269-006-9105-4

Tsakiris G, Vangelis H (2005) Establishing a drought index incorporating evapotranspiration. Eur. Water 9(10):3-11

United Nations Office for the Coordination of Humanitarian Affairs (UN OCHA) (2015) El Niño:snapshot of impact and projected humanitarian needs

Viste E, Korecha D, Sorteberg A (2012) Recent drought and precipitation tendencies in Ethiopia. Theor Appl Climatol 112(3/4):535-551

Viste E, Korecha D, Sorteberg A (2013) Recent drought and precipitation tendencies in Ethiopia. Theor Appl Climatol 112:535-551. https://doi.org/10.1 007/s00704-012-0746-3

WMO (2016) Guidelines on the definition and monitoring of extreme weather and climate events

World Meteorological Organization (WMO), Global Water Partnership (GWP) (2016) Handbook of drought indicators and indices (M. Svoboda and B.a. Fuchs). Integrated drought management Programme (IDMP), integrated drought management tools and guidelines series 2. Geneva

Yue S, Pilon P, Cavadias G (2002) Power of the Mann-Kendall and spearman's rho tests for detecting monotonic trends in hydrological series. J Hydrol 259(1/4): 254-271

Zargar A, Sadiq R, Naser B, Khan FI (2011) A review of drought indices. Environ Rev 19(NA):333-349. https://doi.org/10.1139/a11-013

Degefu MA, Bewket W (2017) Variability, trends, and teleconnections of stream flows with large-scale climate signals in the Omo-Ghibe River Basin, Ethiopia

\section{Publisher's Note}

Springer Nature remains neutral with regard to jurisdictional claims in published maps and institutional affiliations.

\section{Submit your manuscript to a SpringerOpen ${ }^{\circ}$ journal and benefit from:}

- Convenient online submission

- Rigorous peer review

- Open access: articles freely available online

- High visibility within the field

- Retaining the copyright to your article

Submit your next manuscript at $>$ springeropen.com 